\title{
IMAGENS DE PEDRA: UMA TRADUÇÃO INTERSEMIÓTICA DE POESIA E DESIGN GRÁFICO DE AGE DE CARVALHO
}

Lívia Lopes Barbosa*

RESUMO:

Ensaio sobre aproximações entre o mito grego da Medusa e alguns poemas de Age de Carvalho, a partir de imagens da pedra e do espelho, recorrentes em sua poesia.

PALAVRAS-CHAVE: espelho, reflexo especular, pedra, Medusa.

Todo texto constitui uma prática permutativa, jogo feito de citações e transformações, semeado de referências a outros textos e saberes, que se dá, freqüentemente, em mão dupla: aquilo que é citado pode ser convocado como interpretante do texto em questão, ampliando a compreensão deste, bem como endossando-1he o "valor", numa espécie de prestígio por "contato", propiciado pela contigüidade. Em contrapartida, o texto que se serve desse recurso também exerce, junto às citações, um papel de reiterador, funcionando como memento a lembrar/prolongar/validar a existência e a importância daquilo que foi referido. Assim, se não é possível pensar um texto, de qualquer natureza, que não se arrime em outros conhecimentos, ao se tratar do texto literário, isso se torna ainda mais evidente quando, ao ser apreciada a riqueza polissêmica de que é entretecido, assistimos à multiplicação, em sua leitura, de veredas interpretativas que ecoam aqueles outros saberes a que aludimos.

Em nada alheia a esse traço da natureza textual, encontramos na poesia de Age de Carvalho uma imagem cara, a pedra, que fartamente dialoga com outros textos, tanto os de diferentes autores e épocas quanto textos em que a autoria se

* Doutora em Letras: Literatura e outros Sistemas Semióticos (Área de concentração: Literatura Comparada), 2004. 


\section{EMTESE}

Belo Horizonte, v. 9, p. I-28I, dez. 2005

perdeu e que a tradição oral incorporou ao patrimônio intelectual coletivo. A pedra, em Age de Carvalho, assume, desse modo, numerosas feições, icônicas e lingüísticas, cujas significações, tantas vezes eludindo a característica de sucessividade da linguagem verbal, superpõem-se, simultâneas, exigindo do hermeneuta uma atenção redobrada no exame das várias camadas de sentido possíveis. Dentre as formas assumidas pelas imagens relacionadas direta ou indiretamente à pedra, está a do espelho e seu reflexo, em diferentes desdobramentos, de referências ora explícitas, ora sutis, ora incorporadas ao estrato visual do poema, ora evocadas lingüisticamente.

Quando se fala em reflexo especular na poesia carvalhiana, porém, não se pretende remeter a um pretenso espelho pessoano que "reflecte certo; não erra porque não pensa.", mas a imagens virtuais daquilo que é refletido, como o espelho da Alice de Carroll ou as casas de espelhos dos parques de diversões: o reflexo não é o atestado do veraz, mas o descortinar do verossímil, em realidades alternativas; ou a constatação da existência de "versões" do que se chama realidade - mesmo a simetria da imagem devolvida pelo espelho comum, ao fazê-1o de modo invertido, aponta para a desconfiança que deve inspirar a exatidão aparente do objeto do reflexo. Em "Os Incêndios", de Arena, Areia, o espelho e a claridade proporcionada pela reflexão da luz não só não iluminam a compreensão, mas petrificam-na, tornandoa opaca, defrontada a um enigma ("Espelhos espaços claridades: tudo/ convertido na turva escrita das pedras/ onde piso - conciso hieróglifo").

Seja como for, essa relação entre pedra e espelho, secundada pelo caráter dialogal inerente aos textos, acena, por sua vez, para uma irresistível associação entre aqueles elementos e o mito de Medusa, em alguns poemas de Age de Carvalho, como sutis ligações que parecem se cruzar e responder por momentos, ampliando as possibilidades de leitura da poesia carvalhiana. Tal aproximação ensejou certos "passeios" por aquelas veredas interpretativas mencionadas anteriormente, buscando apreciar alguns pontos de contato que nos parecem emergir aqui e ali, entre a lenda e versos de Age de Carvalho. Para tanto, recapitulemos, resumidamente, o que nos conta o mito grego.

Filha de Fórcis e de Ceto, divindades marinhas, Medusa era uma das três Górgonas, juntamente com Esteno e Euríale. Única mortal dentre elas e sendo uma das mais conhecidas e temidas, Medusa tinha cobras em lugar da cabeleira e possuía 
poderes tão extraordinários que, mesmo depois de morta, podia petrificar quem olhasse para sua cabeça. Igualmente, uma mecha de seu cabelo afugentava qualquer exército invasor e seu sangue tinha o dom de matar e ressuscitar pessoas, dependendo de que veia ele proviesse. Perseu, filho de Zeus e de uma mortal, foi encarregado pelo rei Polidectes de dar cabo do monstro. Para a realização da tarefa, apoiou-se em seu pai divino, que The enviou o socorro de Hermes, Atena, Hefaistos e Hades. De Hades, recebeu um capacete que tornava invisivel quem o usasse. Deu-1he Atena um broquel tão polido que mais parecia um espelho. Hermes, o mensageiro dos deuses, ofertou-1he um par de coturnos alados, enquanto de Hefaistos, artifice em metais, recebeu uma arma em forma de foice. Munido dos presentes, Perseu foi ao encontro das Gréias (assim chamadas por sua cor cinzenta), irmãs das Górgonas, conseguindo arrancar-1hes o segredo da morada da Medusa, nas imediações do paîs das Hespérides. Ocultado pelo capacete e voando com os coturnos alados, instruído por Atena usou o escudo como espelho, de forma a guiar-se pelo reflexo do monstro, evitando olhá-10 diretamente, para proteger-se da petrificação. Assim decepou-1he a cabeça e, do pescoço cortado, emergiram Pégaso, o cavalo de asas, e o guerreiro Crisaor.

De imediato, algumas informações fornecidas pelo mito suscitam observações que se aplicam, de maneira geral, à criação poética e, em particular, a alguns traços da poesia de Age de Carvalho. Em primeiro lugar, nos deteremos no deus Hermes, cujo nome provavelmente terá vindo de herma, palavra grega que designava os montes de pedra usados para indicar os caminhos, razão pela qual, também, era considerado protetor das estradas e dos viajantes. Reverenciado como deus da fertilidade, qualidade estreitamente relacionada à criação artística e, por extensão, à criação poética, era, também, o deus da palavra, da eloqüência, da comunicação, oral ou escrita, característica que o aproximava tanto da literatura e da oratória quanto do comércio e do roubo (estes últimos podendo aplicar-se, de igual modo, às palavras, no que diz respeito à troca e à apropriação de outros textos, outros discursos, velada ou ostensivamente).

Talvez por sua facilidade de comunicação e domínio do verbo, Hermes tenha sido assimilado à tarefa de mensageiro dos deuses, portando um caduceu, bastão de ouro cujas serpentes entrelaçadas e encimadas por um par de asas são uma estilização do distintivo característico dos arautos gregos, que era uma vara de 


\section{EMTESE}

Belo Horizonte, v. 9, p. I-28I, dez. 2005

salgueiro à qual se cruzavam duas fitas. Considerado também patrono menor das artes, foi o criador de alguns instrumentos musicais que inspiraram Apolo (a lira é de sua invenção, bem como a flauta, adquiridas por Apolo, que trocou esta última pelo caduceu usado por Hermes). Finalmente, além de arauto, outra atribuição bastante conhecida de Hermes é a de psicopompo ou condutor das almas dos mortos para o Mundo Inferior, regido por Hades. Polivalente e ambígua, a figura de Hermes é carregada tanto de atributos positivos quanto negativos, coadunando-se com sua posição de mensageiro dos deuses e, freqüentemente, mediador entre homens e deuses, o que, por sua vez, ajusta-se à concepção amplamente difundida do poeta como um porta-voz dos anseios e sonhos da humanidade (em Ce siècle avait deux ans, Victor Hugo descrevenos esse papel: "Mon âme aux mille voix, que le Dieu que j'adore/ Mit au centre de tout comme un écho sonore.").

A Medusa é, da mesma maneira, figura imersa em ambigüidade. Seu nome, em grego, quer dizer "a que protege" (e, efetivamente, Atena, após a morte da Medusa, colocou sua cabeça em uma égide. Em outra tradição, ela teria sido enterrada numa praça de Atenas, para proteger esta cidade) e, ainda, "a reguladora, a que reina". Este é o motivo pelo qual a cabeça da górgona (ou gorgoneion) era freqüentemente colocada em templos e túmulos e nos escudos dos soldados. Por outro lado, a palavra "górgona", de gorgos, significa "aquilo que é terrível, que provoca horror", conjugando na mesma figura a noção positiva da proteção e a negativa, do medo profundo. Uma das versões da lenda ainda descreve a Medusa (Fig. 1) como uma linda jovem de bela cabeleira, da qual se orgulhava e que foi castigada em sua vaidade, por Atena, transmutada em monstro de cabelos de serpente e da qual ninguém se aproximaria, tanto pelo aspecto terrível quanto pela faculdade de petrificar pelo olhar. Dando continuidade aos contrastes de que se reveste a personagem, foi, então, de um ser monstruoso como ela que brotou o belo cavalo alado que passou a habitar o monte Helicon, residência das nove musas, fazendo conviver antiteticamente monstruosidade e beleza, rigidez pétrea e inspiração criativa.

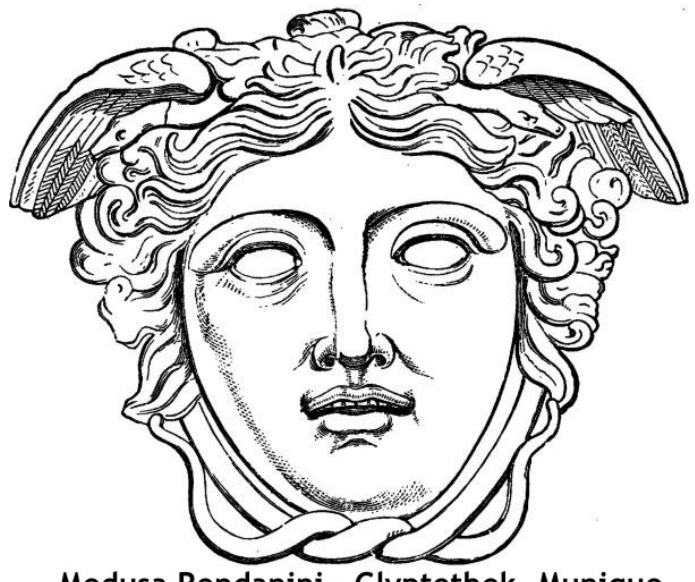

Medusa Rondanini - Glyptothek, Munique

Fig. 1 
Em Age de Carvalho, sobretudo nos poemas de Arena, Areia, assistimos a uma insistente "litomorfização" de seres e coisas que, sob a aparência pétrea, são alimento ("pasto de pedras"), fazer poético ("Aflorar da rocha - / promessa, metáfora"), "pele monolítica" que é também superfície de escrita, fragmento que é tanto ruína quanto material de construção ("De areia era a sombra / coroando a pedra"), vida latente ("Assoprada semente / celebrada sempre em ti") e, também, lápide: "(uma pedra baixando o corpo, / uma palavra perdida / baixando à pedra)". Como não relacionar esse "medusamento", na expressão de Benedito Nunes (Nunes, 1971: 169), com o mito grego que, por sua vez, oferece outras nuanças, das quais reteremos algumas para este breve ensaio?

Em Arena, Areia, o poema "É" parece anunciar o início do mito da Medusa, associado, já no primeiro verso, ao ambiente marinho de seus pais Fórcis e Ceto ("É a praia que chama,/ o mar do sempre, sêmen"). A praia é feita de água e pedra pulverizada - areia - da qual provirá o olhar petrificador, água que, se pela ação erosiva corrói a pedra, também a "prepara", na Medusa por nascer. Neste mar seminal, num tempo mítico desatrelado da cronologia, o presente do indicativo pontua a atemporalidade na forma verbal polivalente que tanto descreve o agora quanto 0 passado e o futuro. 0 poema prossegue, referindo, adiante, "entre onda e vaga", a forte e impetuosa Esteno e a errante Euríale ("a cheia de força" e "a que vaga", como significam seus nomes gregos), parecendo prever, em seguida, de modo obscuro, a ulterior intervenção de Perseu e seu escudo reluzente, projeções na "água aliterada/ aqui, o espelho cifrado/ informado rosto/ onde/ branco mira-se o alvo nome". Mais uma vez, o espelho, na poesia carvalhiana, não devolve a imagem, mas a oculta e confunde, enigmático, em linguagem de pítia: há um alvo por atingir, que a imagem refletida sugere mas não desvela. A antevisão prossegue, antecipando o final do embate futuro: "É/ a praia/ / o corporal tempo e leito/ que chama/ / vaga onda nada", resumindo o fim-começo que aguarda Medusa (esta tem os signos de sua morte - gotas de sangue - acolhidos pelo mar, quando Perseu sobrevoa as águas trazendo às mãos a cabeça decapitada, devolvendo parte da górgona à sua origem marinha, estabelecendo a circularidade perpetuadora do mito).

Mais adiante, no mesmo livro, em "Englischer Garten, München", Perseu aparenta sobrevoar o jardim das Hespérides, as ninfas guardiãs da árvore dos pomos 


\section{EMTESE}

Belo Horizonte, v. 9, p. I-28I, dez. 2005

de ouro de Zeus, em busca das Gréias, as irmãs cinza que o informarão sobre a morada da Medusa. Estamos diante do primeiro passo rumo à morte e à criação que acontecerão em breve (morte do monstro petrificador, para que se dê o nascimento do cavalo alado que mora junto à inspiração), numa descrição do fazer poético, em que a afasia pétrea é substituída pela palavra que ganha asas: "Aérea-/ alumbrada/ mão do desastre,/ / que sobrevoou o verão da fruta/ e se fechou na sombra/ jovem da pedra,/ na jura grisalha que nos acolhia/ / (sem sim/ nem não, poesia)". Os versos de "Englischer Garten, München" estabelecem, de certa maneira, uma transição para a chegada ao território da Medusa, em "Os Jardins e a Noite", também de Arena, Areia, em que "As feras/ dormem nuas em sua severa/ inconsciência de músculos. Eternas/ estátuas que ornam estes jardins/ esquecidos mas reais: esferas do luto".

De "Esse", em Caveira 41, emergem várias serpentes, símbolos tradicionais da sabedoria e do horror, saídas tanto do caduceu hermético (que virá a ser utilizado, depois, como insígnia de Asclépio, signo de cura e vida) quanto da cabeça da górgona. Aí estão vida e morte entrelaçados uma vez mais, numa alusão à permanência e à eternidade, roda dinâmica a girar em incessante recomeço de uroboro: "ESSE o tempo-/ em-sempre da serpente,/ seu recobrado sentido/ circular nas glebas/ do sangue." As serpentes reinsinuam-se no poema, embutidas em palavras ("recobrado"), através do formato sinuoso da letra "s" e da aliteração sibilante dos versos, por seu turno repetidas no título ambíguo do poema que, sob sua forma, abriga tanto o pronome demonstrativo quanto o nome da letra-serpente e o verbo ser, na atemporalidade do presente e na indeterminação do sujeito ("aqui, é-se").

No mesmo poema, Hermes psicopompo se faz anunciar pelas serpentes do caduceu, assim como nelas, subentendidos, estão o conhecimento de Atena e o Mundo Subterrâneo de Hades (Age de Carvalho, em entrevista à Folha de S. Paulo, em 19 de agosto de 2003, refere-se ao poeta como um "acossado, falando para todos e ninguém, pagando a crédito a sua entrada no Inferno (que é a linguagem)"), para cujo ingresso o veneno-palavra é passaporte. No sangue da Medusa condensam-se, portanto, morte e ressurreição, de acordo com a veia (verve?) de onde brote, catalisadas pela picada da curiosidade/tentação que representa a perspectiva de saber: "Chão,/ subcutâneo, chão -/ aqui se apaga/ a veia vida/obra,/ aqui a cobra/ (intra-/ vírgula/ venenosa) insinua/ entre ramas brilhantes/ seu eterno s:/ / aqui, é-se." 
De volta a Arena, Areia, as serpentes se encontram em outro poema, "Cobra", não apenas lingüística, mas visualmente (Fig. 2), com o traçado das estrofes estabelecendo uma estrutura sinuosa, "refletindo" reiteradamente 0 tema. Em "Cobra", a própria palavra se torna a serpente e envenena a obra, enroscando em seu nó apertado autor e leitor ("era a palavra,/ a mais alta/ que embaixo/ rastejava à cova/ defendida por ninguém,/ o/ oco da obra/ envenenada, palavra/ que se come pelo rabo/ (um/ em um/ éramos/ nó/s)/ cobra"). Nesse movimento, anuncia e denuncia o aliciamento e fusão do leitor, do autor e da obra, em ação cooperativa, num contínuo fazer e refazer desencadeados pela operação interpretativa.

0 Perseu do mito parece reunir em si tanto os atributos daqueles que 0 ajudam quanto daquela a quem ele combate, esboçando um perfil metafórico do poeta: é aquele que é assistido pela habilidade vocabular e musical de Hermes, capaz de pairar sobre as coisas, para que o distanciamento lhe permita melhor interrogá-las; é amparado pelo desejo de saber personificado por Atena, sem deixar-se por ele ofuscar, servindo-se do escudo que reflete seu objeto, como as sombras da caverna platônica; apadrinhado por Hades, não se contenta com a superfície das coisas e sonda-lhes os veios subterrâneos dos sentidos sutis, lidando com o "inferno" da linguagem; Hefaistos forja-1he o instrumento que irá "decapitar" os excessos das palavras, em meticuloso trabalho poético. Finalmente, da Medusa herdou o olhar petrificador que, no entanto, não é o olhar da morte, mas o da redução das coisas à sua expressão basilar: transformadas em pedra, tornam-se material de construção,
Cobra

intimo raro,

um em um éramos

mais alta $c$ a estaçầo,

o ereto verão da devora,

tensos sobre o grào anel da prai

emblemados contra si contra

um coraçào de madeira

enredando as toscas iniciais

no lenho torturado

para

frase barrenta do nio

ir, o vindo

se ouvia-se inacabada, indo, in-

àgua esclarecida em negror

a margem do conhecimento

do rio, rio

sendo

ou

era a palavra,

a mais alta

que embaixo rastejava à cova

defendida por ninguém.

oco da obra

envenenada, palavra

come pelo rabo

cm

éramos

s)

cobra

Fig. 2
Folha em-folh 


\title{
EMTESE
}

Belo Horizonte, v. 9, p. I-28I, dez. 2005

descarnadas e aptas a receber formas novas, frescor significativo, onde se enroscam o encanto e o perigo das serpentes que acenam com seu venénum filtro mágico, remédio e veneno de que são feitas as palavras, de que se tece a literatura. Eis-nos capturados numa viagem mítica a nos conduzir para além da face utilitária dos nomes, guiados por jogos de espelhos que multiplicam rumos, refletindo possibilidades interpretativas.

\author{
ABSTRACT : \\ Essay featuring correlations between the Greek myth of \\ Medusa and selected poetry by Age de Carvalho, based on \\ the images of the stone and the mirror, recurrent in his \\ writings.
}

KEY WORDS: mirror, specular reflex, stone, Medusa.

\section{REFERÊNCIAS BIBLIOGRÁFICAS}

ALVES, Rogério Eduardo. Age de Carvalho esculpe novas elipses. Folha de S. Paulo, São Paulo, 19 ago 2003. CARValho, Age de. Arena, Areia. Belém: Grápho, 1986. - Ror: 1980-1990. São Paulo: Duas Cidades; Secretaria de Estado da Cultura, 1990. - Caveira 41. São Paulo: Cosac \& Naify, 2003.

DiCIONÁRIO DE MITOLOGIA GRECO-ROMANA. São Paulo: Abril Cultural, 1973.

NUNES, Benedito. João Cabral de Melo Neto. Petrópolis: Vozes, 1971. 